\title{
Evaluation of the Adsorption Capacity of Banana Peel in the Removal of Emerging Contaminants present in Aqueous Media - Study based on Factorial Design
}

Priscila Afonso Rodrigues de Sousa ${ }^{1 *}$, Liliam Tavares Furtado1, João Luiz Lima Neto', Fabiano Mendonça de Oliveira ${ }^{2}$, José Guilherme Martins Siqueira ${ }^{1}$, Luiz Fernando Silva ${ }^{1}$, Luciana Melo Coelho ${ }^{1}$ ${ }^{1}$ Federal University of Goiás, Regional Catalão, Catalão, GO, 75704-020, Brazil. *rodriguessousa41@hotmail.com ${ }^{2}$ Federal University of Uberlândia, Monte Carmelo Campus, IQUFU, Monte Carmelo, MG, 38500-000, Brazil.

\section{Graphical Abstract}

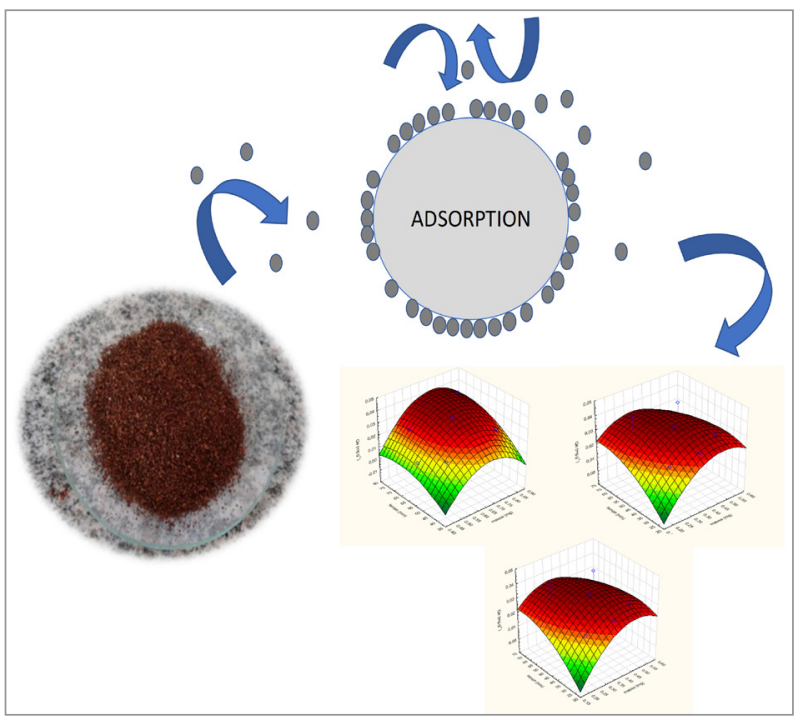

Adsorption of emergent contaminants using banana peel as adsorbent and factorial planning method with response surface analysis
A simple procedure was developed with the adsorption of the compounds estrone (E1), 17a-ethinylestradiol (EE2), and sulfamethoxazole (SMX) in aqueous solutions using banana peel as an adsorbent material. Adsorbent mass, contact time, and granulometry were studied through multivariate design. The proposed adsorbent was advantageous, with removal exceeding $80 \%$ for E1 and EE2 and $70 \%$ for SMX in the analysed samples. Studies of adsorption isotherms demonstrate adequacy compared to the Freundlich model, and kinetic studies indicate adsorption through the pseudosecond order model $(\mathrm{E} 1=0.9999$, EE2 $=0.9999$, and SMX = 0.9999). The developed method was successfully applied in supply water samples and accuracy was evaluated through recovery tests, with recovery ranging from $70 \%$ to $96 \%$.

Keywords: Adsorption, emerging contaminant, multivariate design, hormone, antibiotic

\section{INTRODUCTION}

The contamination of water resources has long been a major concern. According to the World Health Organization (WHO), since 1970 intense modifications observed in the environment have been caused by the presence of natural and synthetic contaminants, especially in groundwater and surface waters, at concentrations of $\mathrm{pg} \mathrm{L}^{-1}$ to $\mathrm{ng} \mathrm{L}^{-1}$. Compounds arising from human activities and found in the environment are known as emerging contaminants [1]. Many compounds are classified as emerging contaminants, particularly toiletries, pharmaceuticals, hormones, products for veterinary use, drugs, additives, and beauty and cleaning products [2]. Antibiotics used in the treatment of infections and pharmaceuticals represent a class of emerging contaminants classified as endocrine disrupters or endocrine interfering. According to the Environmental Protection Agency (EPA), "disrupter or endocrine interfering are exogenous agents that interfere in the synthesis, secretion, transport, binding, action or elimination of natural hormones in the body which are responsible for the maintenance, reproduction, development and behaviour of organisms" [3]. Estrone (E1) and 17a-ethinylestradiol (EE2) compounds are classified as endocrine disruptors when found in the environment. 
Estrone is a derivative of the hormone $17 \beta$-estradiol, which is present in females and males organisms [4]. The daily excretion of this compound in domestic sewage is variable; pregnant women excrete 600 $\mu \mathrm{g}$ per day, while men excrete only $3.9 \mu \mathrm{g}$ per day [5,6]. The compound $17 \alpha$-ethinylestradiol (EE2) is a synthetic hormone found in contraceptive pills, which are being discarded in the environment through urine and feces [7]. The sulfonamides are compounds that act as microbial inhibitor agents on the bacteria in the treatment of intestinal and respiratory infections $[8,9]$. The antibiotic sulfamethoxazole $(\mathrm{SMX})$ is a compound of the sulfonamide class with bacteriostatic function that is consumed by patients with intestinal infections [11]. This compound is found in urine at concentrations of $10-30 \%$ of the initial concentration consumed [12]. The study of these compounds is necessary because they can be found in the environment due to the excretion of animals or indiscriminate disposal of sewage. Antibiotics, such as sulfamethoxazole, were found in effluents from different countries (France, Greece, and Germany) at concentrations of $0.01-0.41 \mu \mathrm{g} \mathrm{L}^{-1}$ [16]. The compound EE2 was found at concentrations of 0.2-0.45 $\mu \mathrm{g} \mathrm{L}^{-1}$ in Italy, the Netherlands, England, and Germany. Estrone was found at concentrations of 0.5$0.027 \mu \mathrm{g} \mathrm{L}^{-1}$ in Italy, the Netherlands, and Germany [17].

The conventional treatment of water, sewage and industrial effluents are not efficient in the removal of these compounds, requiring the development of more efficient techniques. A proposed method to remove these compounds from aqueous environments is the use of natural adsorbents for the treatment of contaminated water [18-20]. Activated carbon is an adsorbent efficiently used for the removal of different compounds (organic or metallic). However, its cost is higher than most of the natural adsorbent materials cited in the scientific literature. In this context other natural adsorbents have been extensively researched, such as coconut shell, palm and bamboo, orange skin, and rice husk [21-24]. Banana peel, which is usually used as fertilizer or animal feed [25], is a type of natural adsorbent that has been used in the development of analytical methods.

Several studies have shown the use of banana peels to remove organic compounds and metals, demonstrating the efficacy of this adsorbent material in the removal of different compounds. Gupta [26] proposed an efficient and inexpensive approach to remove polycyclic aromatic hydrocarbons from an aqueous system using activated charcoal synthesized from banana peel. The results demonstrated the removal of up to $95 \%$ of the hydrocarbons at a concentration of $20 \mathrm{mg} \mathrm{L}^{-1}$ when using around $2 \mathrm{mg}$ of adsorbent material and a contact time of $80 \mathrm{~min}$. Silva et al. [27] developed a method using banana peel in the removal of the pesticides atrazine and ametryne from river and treated waters. In their study, low limit of quantification (LOQ) values were achieved $\left(0.10\right.$ and $\left.0.14 \mu \mathrm{g} \mathrm{L}^{-1}\right)$ for both pesticides with removal efficiency greater than $90 \%$, thus demonstrating the efficiency of banana peel as a bioadsorbent for aqueous systems. The potentiality of the banana peel as adsorbent material was also evaluated by the adsorption of Congo red dye from an aqueous solution [28]. This adsorption study was performed through the evaluation of operational variables such as $\mathrm{pH}(\mathrm{pH} 10)$, adsorbent concentration (increasing the adsorbent concentration from $0.5 \mathrm{~g} / 80 \mathrm{~mL}$ to $1.5 \mathrm{~g} / 80 \mathrm{~mL}$ resulted in the percentage of adsorption ranging from $63.32 \%$ to $75.26 \%$ ), contact time (90 minutes) and temperature $\left(40{ }^{\circ} \mathrm{C}\right)$. The adsorption equilibrium of the dye was evaluated by the Freundlich and Langmuir isothermal models. The results revealed that the isotherm and the adsorption kinetics of the dye fit well with the Langmuir isotherm and the pseudo-second order kinetics, respectively. The adsorption capacity of the dye was recorded as $1.727 \mathrm{mg} / \mathrm{g}$ [28].

A bibliographic search in the Web of Science database for the keywords "banana peel", "sulfamethoxazole", "estrone", and "ethinylestradiol" showed no published research article in which banana peel is used for the adsorption of E1, EE2, or SMX, demonstrating the possibility and necessity of studying the potential of banana peels in the removal of these compounds.

Thus, in this study a methodology for the removal of the emerging contaminants estrone, ethinyl estradiol, and sulfamethoxazole in water was developed using banana peel as a biosorbent. The determination of the organic compounds in water samples was performed by high performance liquid chromatography (HPLC). Parameters influencing adsorption were studied through multivariate design. 


\section{MATERIALS AND METHODS}

\section{Solutions and adsorbent material preparation}

The compounds estrone (E1) ( $\geq 99 \%$ purity), 17a-ethinylestradiol (EE2) ( $\geq 98 \%$ purity), and sulfamethoxazole (SMX) (99\% purity) were acquired from Sigma-Aldrich. The working solutions were obtained by diluting a stock solution of $100.0 \mathrm{mg} \mathrm{L}^{-1}$ of each compound prepared with ultrapure water obtained by a water purification system from Gehaka (São Paulo, Brazil). Before use, the laboratory glassware was left in a $10 \%(\mathrm{v} / \mathrm{v})$ aqueous solution of nitric acid overnight, and rinsed with deionized water the next day.

The adsorbent material was purchased from a trade, washed with distilled water and oven dried for $24 \mathrm{~h}$ at $105{ }^{\circ} \mathrm{C}$. After drying, the peels were crushed in a blender (Black \& Decker, São Paulo, Brazil) and sieved in different grades (60 to 100 mesh). This material, designated as "banana peel in natura", was submitted to physical-chemical analysis and used in adsorption tests.

\section{High performance liquid chromatography (HPLC)}

A high-performance liquid chromatography system (Shimadzu Model SPD-20A) coupled with an UV-Vis detector was used for the chromatographic analyses. The column used was octadecyl (C18) $(250 \times 460 \mathrm{~mm} \mathrm{ID}, 5 \mu \mathrm{m})$, the mobile phase was $\mathrm{MeCN} / \mathrm{H}_{2} \mathrm{O}(50: 50 \mathrm{v} / \mathrm{v})$, the flow rate was $1.0 \mathrm{~mL} \mathrm{~min}^{-1}$, the injection volume was $20.0 \mu \mathrm{L}$, and the wavelength was $212 \mathrm{~nm}$.

The quantification was performed by external standardization through the calibration curve for each compound at different concentration values, prepared by diluting the stock solution at a concentration of $100.0 \mathrm{mg} \mathrm{L}^{-1}$ of each compound. The retention times of E1, EE2, and SMX were 5.3, 4.8, and 3.2 min, respectively.

\section{Adsorbent characterization}

The functional groups present on the surface of the adsorbent were identified by infrared spectroscopy. An IR Prestige-21 infrared spectrophotometer (Shimadzu) was used in this study. The adsorbent material was compressed in a $\mathrm{KBr}$ tablet $(10: 1 \mathrm{KBr} /$ sample) and the analyses were performed in the wavelength range of $4000-500 \mathrm{~cm}^{-1}$ with a resolution of $4 \mathrm{~cm}^{-1}$.

Scanning electron microscopy (SEM) was performed for observation and analysis of the microstructural characteristics of the adsorbent under study. The micrographs were obtained using a scanning electron microscope (model JSM-6610, Jeol) equipped with EDS (energy dispersive spectroscopy) (NSS Spectral Imaging, Thermo Scientific) in the High Resolution Microscopy Laboratory of the Federal University of Goiás (LabMic, UFG), Samambaia Campus (Goiânia, GO, Brazil). Prior to the analyses, the samples were coated with a thin film of gold using a deposition system (Desk V, Denton Vaccum). The samples were fixed in a copper sample port with the aid of carbon tape.

\section{Study of $\mathrm{pH}$ influence on adsorption}

The influence of $\mathrm{pH}$ on the adsorption was studied by tests performed with $500.0 \mathrm{mg}$ of the adsorbent (100 mesh) and $25.0 \mathrm{~mL}$ of the water sample at different $\mathrm{pH}$ values $(2,4,6$, and the natural $\mathrm{pH}$ of the mixture of $\mathrm{E} 1, \mathrm{EE} 2$, and $\mathrm{SMX}$ in water, $\mathrm{pH}=5.25)$, and fortified with $\mathrm{E} 1, \mathrm{EE} 2$, and $\mathrm{SMX}$ at a concentration of $1.0 \mathrm{mg} \mathrm{L}^{-1}$.

The samples were shaken at $150 \mathrm{rpm}$ for $60 \mathrm{~min}$ using an orbital shaker table, filtered and analysed by HPLC. All tests were performed in triplicate $(n=3)$ at room temperature $\left(T_{a m b}=25^{\circ} \mathrm{C}\right)$.

\section{Optimization strategy for the adsorption of E1, EE2, and SMX}

After the $\mathrm{pH}$ optimization, a $2^{3}$ factorial design [three variables, at two levels with their coded values $(+)$ and $(-)$ ] was used to evaluate additional adsorption parameters, such as adsorbent mass $(0.250 \mathrm{~g}$ and $0.500 \mathrm{~g}$ ), granulometry (60 mesh and $100 \mathrm{mesh})$, and contact time (30 min and $60 \mathrm{~min})$. Ten experiments were performed with two central points for each parameter. 
The factorial design experiments were made with $25.0 \mathrm{~mL}$ of a solution containing a mixture of E1, EE2, and SMX at a concentration of $500 \mu \mathrm{g} \mathrm{L}{ }^{-1}$. The mixtures in the test conditions were placed on an orbital shaker table at $150 \mathrm{rpm}$, with subsequent filtration and quantification by HPLC.

\section{Isotherms, adsorption kinetics, and thermodynamic parameters}

The adsorption kinetics tests were done using $25.0 \mathrm{~mL}$ of the solution containing E1, EE2, and SMX at a concentration of $500.0 \mu \mathrm{g} \mathrm{L}^{-1}$, and the mass was defined by factorial design studies at the following different shaking times: 5, 10, 15, 30, 45, 60, 75, 90, 120, 180, and $240 \mathrm{~min}$. The solutions were filtered and analysed by HPLC.

The adsorption isotherms were obtained using the mass and the optimized contact time through a factorial design with $25.0 \mathrm{~mL}$ of the solution containing the three compounds in different concentration ranges for E1 (1.5-12.0 mg L-1), EE2 (1.5-4.0 mg L-1), and SMX (1.5-10.0 mg L-1).

The amount of compound adsorbed at the equilibrium time represents the adsorption capacity, Qe $(\mathrm{mg} / \mathrm{g})$, determined by equation (1) as follows:

$$
\mathrm{Qe}=\frac{\left(\mathrm{C}_{0}-\mathrm{Ce}\right) \mathrm{V}}{\mathrm{W}}
$$

where $\mathrm{C}_{0}$ and $\mathrm{Ce}\left(\mathrm{mg} \mathrm{L}^{-1}\right)$ are the initial and equilibrium adsorbate concentrations, respectively; $\mathrm{V}$ is the volume of the solution $(\mathrm{L})$; and $\mathrm{W}$ is the mass of the adsorbent $(\mathrm{g})$.

\section{Samples}

The water samples were collected after treatment at the Water Treatment Station (ETA) in the city of Catalão, GO, Brazil, and before distribution to the population of this city. A total of three samples were collected. The samples were loaded in amber glass bottles with caps, properly identified with name, collection place, date and time, and were kept in a Styrofoam container with ice for transportation. In the laboratory, the capped amber glass bottles were placed in a refrigerator at approximately $4^{\circ} \mathrm{C}$. The samples were analysed in less than $24 \mathrm{~h}$ after collection.

Prior to the analyses, the water samples were filtered through $0.45 \mu \mathrm{m}$ membranes to remove suspended particles. The $\mathrm{pH}$ of the samples was measured and corrected to 6.0 using $\mathrm{NaOH}$ or $\mathrm{HCl}$ $\left(0.1 \mathrm{~mol} \mathrm{~L}^{-1}\right)$ solutions. Aliquots were removed for analysis.

\section{RESULTS AND DISCUSSION Adsorbent characterization}

The spectrum obtained in the medium infrared region (FT-MIR) shows the functional groups present in the studied adsorbent (Figure 1). 


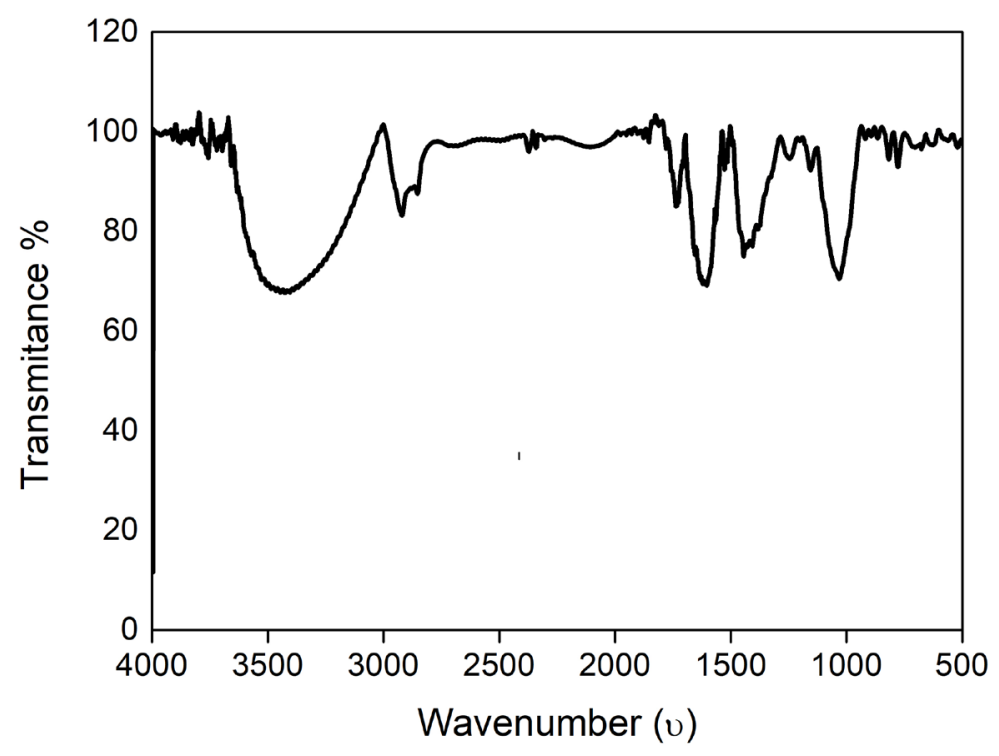

Figure 1. Infrared spectrum of the banana peel.

The infrared spectrum of the banana peel shows the presence of some bands typical of different functional groups. The band at $884 \mathrm{~cm}^{-1}$ can be attributed to amine deformations, according to Memon et al. [29], and primary and secondary alcohols cause the band at $1059 \mathrm{~cm}^{-1}$. The band at $1104 \mathrm{~cm}^{-1}$ can be attributed to chemical bonding $\mathrm{S}-\mathrm{OH}$ or $-\mathrm{P}=\mathrm{O}$ groups, according to Corti et al. [30]. The carboxyl group is indicated by the band at $1300 \mathrm{~cm}^{-1}$. Vibration bands at $1525 \mathrm{~cm}^{-1}$, reported by Akhter et al. [31], are assigned to $-\mathrm{NO}_{2}$ groups. Bands at $1625 \mathrm{~cm}^{-1}$ may be assigned to a combination of $\mathrm{C}=\mathrm{C}$ stretching vibrations of the aromatic ring structures or to systems such as diketone, ketoester, and quinone [32]. The band at $1734 \mathrm{~cm}^{-1}$ can be attributed to axial deformation vibrations of $\mathrm{C}=\mathrm{O}$ in carboxylic acids or esters presents in the banana peel [25]. The band at $1750 \mathrm{~cm}^{-1}$ can be attributed to an ester, the band at $2927 \mathrm{~cm}^{-1}$ is due to methylcellulose, and the band at $3400 \mathrm{~cm}^{-1}$ is assigned to hydroxylic groups [33].

SEM analyses identified the morphological properties of the adsorbent material surface. Figure 2 shows an irregular porous surface (micro and macro pores) with the presence of some cracks and recesses, characteristics that favour adsorption. In the analysis of other materials (sugar cane and vegetable sponge) used in adsorption studies, similar results were observed [34,35].

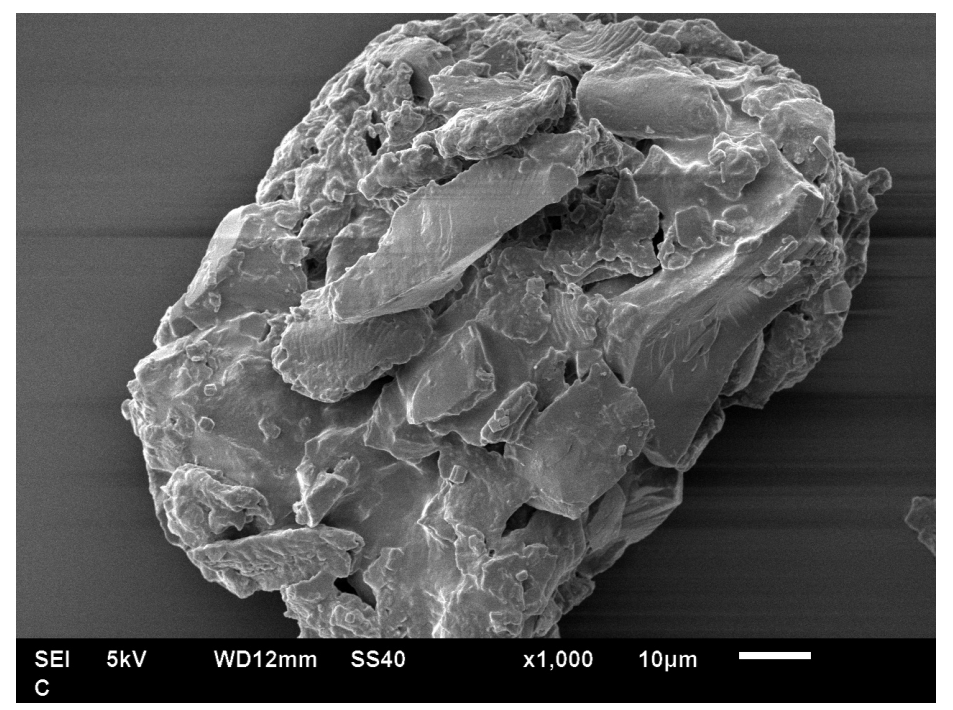

Figure 2. Scanning electron microscopy (SEM) micrographs of banana peel. 


\section{Influence of $\mathrm{pH}$ on adsorption}

The biomass surface is composed of proteins, lipids, and carbohydrates, which are responsible for the surface charge of particles due to the dissociation of functional groups. This dissociation is $\mathrm{pH}$ dependent.

To evaluate the influence of $\mathrm{pH}$ on the adsorption of compounds E1, EE2, and SMX, adsorption tests were made with solutions at different $\mathrm{pH}$ values. The results are shown in Figure 3.

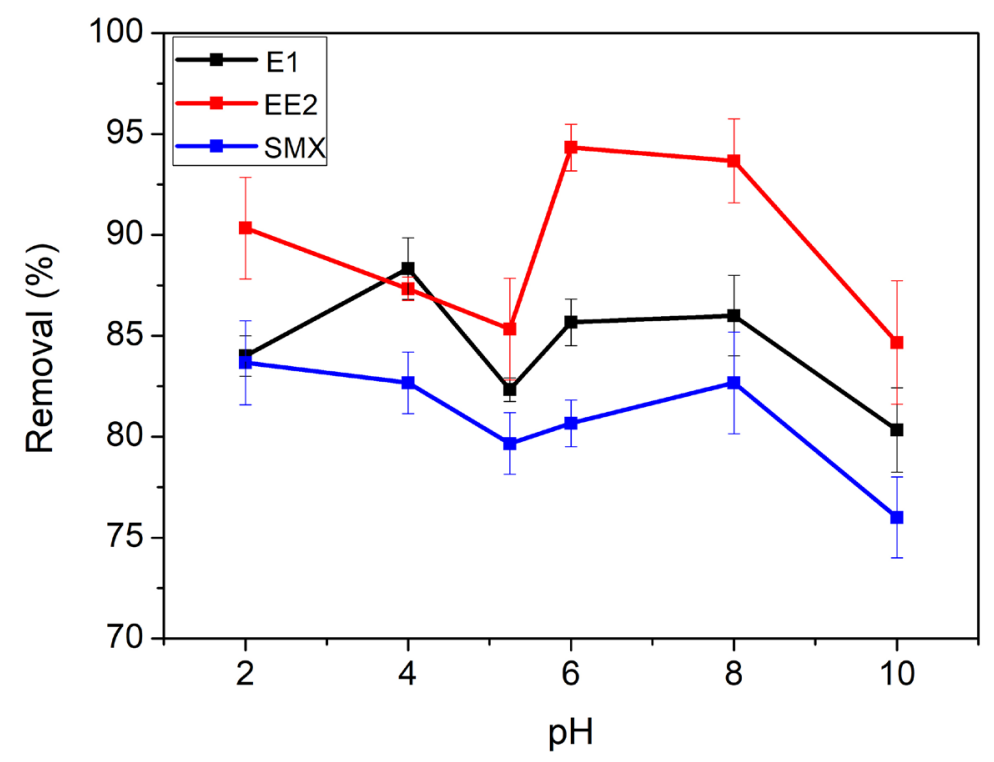

Figure 3. Study of the influence of $\mathrm{pH}$ on the adsorption process of the compounds estrone (E1), ethinylestradiol (EE2), and sulfamethoxazole (SMX) $(n=3)$.

Good removal rates of the compounds studied (>70\%) were observed. The study of adsorption as a function of $\mathrm{pH}$ variation shows that from the initial concentration of $1.0 \mathrm{mg} \mathrm{L}^{-1}$ for each compound, the maximum amount of adsorption of compounds EE2, E1 and SMX was $0.93 \mathrm{mg} \mathrm{L}^{-1} ; 0.88 \mathrm{mg} \mathrm{L}^{-1}$ and 0.82 $\mathrm{mg} \mathrm{L}^{-1}$, respectively, demonstrating efficient removal. This is due to the presence of a greater amount of hydroxyl and carbonyl groups on the surface of the adsorbent material, which was observed in the infrared spectrum.

The variation of the adsorption rate of each compound in the different $\mathrm{pH}$ values was small, not exceeding $10 \%$. Therefore, considering that the $\mathrm{pH}$ of a sample for HPLC chromatographic column analysis should not be too acidic nor too basic, the $\mathrm{pH} 6.0$ was chosen for the analyses because it was close to the $\mathrm{pH}$ of the samples in which the method would be applied and the removal rate was greater than $80 \%$. The $\mathrm{pH}$ of the solution was above the point of zero charge (PZC) of the biomass $(\mathrm{pH}=5.6)$ obtained experimentally by the authors, and surface negative charges were present predominantly in dissociated carboxyl and hydroxyl groups, interacting more satisfactorily with positively charged compounds.

Bajpai and Rajpoot (1996) [36] reported that in solutions where the adsorbent is protonated, release of nitrogen-bound hydrogen in the SMX occurs, allowing the electrostatic attraction between the protonated functional group present on the surface of the adsorbent and negatively charged SMX.

At $\mathrm{pH}$ values above 7, interaction of the deprotonated groups present on the surface of the adsorbent occurs with the hydrogen bound to the amino group. At a $\mathrm{pH}$ of 8 , the neutral or deprotonated form (presence of negative charge) prevails, with interaction through hydrogen bonding as well as electrostatic interactions between the deprotonated functional group and the $\mathrm{H}$ present in SMX.

According to Han et al. [37], hydrogen bonding interactions can occur between the phenolic hydroxyl 
of EE2 and E1 and the amide groups present in the active sites of the adsorbents. These interactions are stable between $\mathrm{pH}$ values of 4.8 and 9.1. Furthermore, because of the bioaccumulation capacity of these compounds, they have a strong affinity for solids insoluble in aqueous solutions, contributing to the adsorption [37].

At higher $\mathrm{pH}$ values, there is less protonation of the functional groups, which could lead to greater interaction. In basic medium, there is competition between the hydroxyls and the compounds with the adsorption sites.

According to Marques et al. [38], different interaction mechanisms can occur through hydrogen bonding with primary and secondary amine molecules, as well as hydrophobic interactions by Van der Waals forces and hydrogen bonds [39].

\section{Study of chemical variables in the adsorption process}

The significance of each parameter in adsorption (adsorbent mass, time contact, granulometry) and interactions were determined using $2^{3}$ complete factorial experiments and the response was the adsorption capacity, which is the amount of each compound adsorbed per unit mass of the adsorbent (Qe).

An analysis of variance (ANOVA) test was performed to determine if the studied experimental factors were significant (with a value of 0.05 ) in the performance of the adsorption system. The main effects and their interactions are described in the Pareto graphs shown in Figure 4. The experiments were performed in triplicate and the lack of adjustment was evaluated through the ANOVA table, where the R-sqr value was 0.88066 and residual MS was equal to 0.0007841 .

(a)



(b)

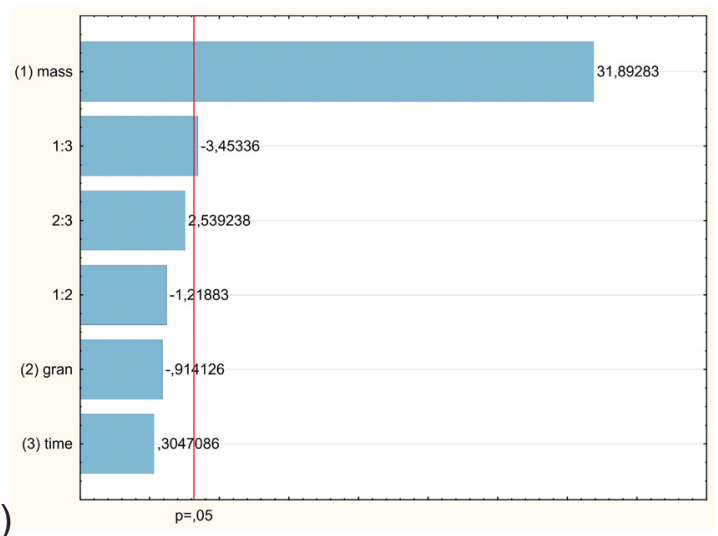

(c)

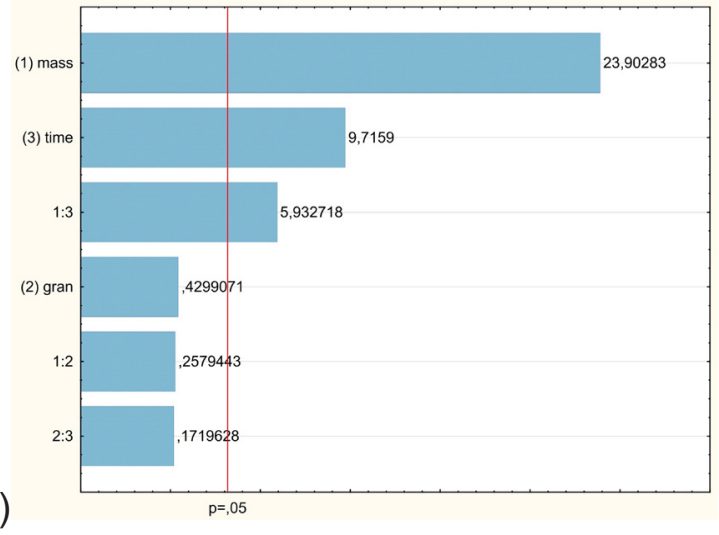

Figure 4. Pareto chart of the standardized effects for the variables of adsorption systems $\mathrm{E} 1$ (estrone) (a), EE2 (ethinylestradiol) (b), and SMX (sulfamethoxazole) (c) with the banana peel adsorbent $(n=3)$. 
Analysing the Pareto graphics for the isolated variables (1, 2, and 3), it was observed that the adsorbent mass variable was significant for the three compounds studied and the contact time variable was only significant for the compound SMX. As the granulometry variable had no significant effect on the adsorption of the compounds, its value was defined based on the lower reagent consumption, and the adsorbent was used in the 100 mesh granulometry for the other analyses.

Considering the interactions between the variables $(1: 2 ; 1: 3 ; 2: 3)$ in the pareto graph, only the interaction mass and time (1:3) presented significance $(p>0.5)$, thus requiring a study to obtain optimum final conditions. The other interactions (mass versus granulometry and time versus granulometry) had no significant effect on any of the compounds.

The interaction between mass and time was evaluated through the construction of the response surface using CCD (central composite designer). The ten experiments required to construct the response surface, as well the obtained Qe values, are shown in Table I.

Table I. Matrix for the optimization of adsorbent mass and contact time $(n=3)$.

\begin{tabular}{lccccc}
\hline Experiment & Mass $(\mathbf{m g})$ & Time $(\mathbf{m i n})$ & E1 qe $\left(\mathbf{m g ~ g}^{-1}\right)$ & EE2 qe $\left(\mathbf{m g ~ g}^{-1}\right)$ & SMX qe $\left(\mathbf{m g ~ g}^{-1}\right)$ \\
\hline 1 & 0.2500 & 30.0 & 0.235 & 0.226 & 0.186 \\
2 & 0.2500 & 60.0 & 0.418 & 0.416 & 0.368 \\
3 & 0.5000 & 30.0 & 0.306 & 0.315 & 0.285 \\
4 & 0.5000 & 60.0 & 0.425 & 0.389 & 0.409 \\
5 & 0.1981 & 45.0 & 0.178 & 0.156 & 0.117 \\
6 & 0.5562 & 45.0 & 0.267 & 0.273 & 0.253 \\
7 & 0.3750 & 24.7 & 0.290 & 0.280 & 0.207 \\
8 & 0.3750 & 68.3 & 0.278 & 0.269 & 0.382 \\
$9(0)$ & 0.3750 & 45.0 & 0.346 & 0.357 & 0.368 \\
$10(0)$ & 0.3750 & 45.0 & 0.349 & 0.350 & 0.367 \\
\hline
\end{tabular}

qe: quantity adsorbed in equilibrium $\left(\mathrm{mg} \mathrm{g}^{-1}\right)$

After obtaining the results, a response surface was generated for each compound using the Lagrange criterion, obtaining the maximum and critical values of each variable: mass $0.391,0.390$ and $0.710 \mathrm{mg}$; time 58.663, 53.250 and $62.000 \mathrm{~min} ; 100,100$ and 100 mesh granulometry, respectively, compounds estrone, ethinylestradiol and sulfamethoxazole.

The pareto graph (Figure 4) showed a negative standardized effect for the mass and time interaction for the compounds E1 (-3.52083) and EE2 (-3.45336), indicating that if the adsorbent mass increased, the contact time between the adsorbent and adsorbate must decrease for adsorption to be effective, or vice versa. For SMX, the positive value of the 1:3 interaction (5.932718) indicates that the adsorbent mass and the contact time must be increased simultaneously for adsorption be significant.

Thus, as the values of mass and time are similar for the compounds E1 and EE2 and different for the SMX, and analysing the significance generated by the pareto graph (Figure 4) for the three compounds, the results obtained for the SMX compound were considered as optimized conditions, since the interaction significance for the compounds E1 and EE2 was minimal when compared to the interaction result obtained for the SMX.

As a result of the optimization procedures, the following working conditions were selected: adsorbent mass of $0.710 \mathrm{mg}$, adsorbent granulometry of 100 mesh, and contact time of $62 \mathrm{~min}$. 


\section{Adsorption isotherms}

The adsorption isotherms show the equilibrium between the maximum amount of compound $(\mathrm{mg})$ that is adsorbed by a certain adsorbent mass $(\mathrm{g})$ under certain operating conditions. This allows the observation of the adsorption process equilibrium that occurs without the compound presence in the system solid and liquid phases.

The adsorption data of isotherms were applied to the linearized model of Langmuir (equation 2), Freundlich (equation 3) and Dubinin-Radushkevich (equation 4) represented by the equations:

$$
\begin{gathered}
\frac{C_{f}}{Q e}=\frac{1}{Q_{\text {Max }} b}+\frac{C_{F}}{Q_{\text {Max }}} \\
\log Q e=\log K_{f}+1 / n \log C_{F} \\
\ln (\mathrm{qe})=\ln \left(\mathrm{X}_{\mathrm{m}}\right)-\mathrm{kE}^{2}
\end{gathered}
$$

where $Q_{\text {Max }}$ is the Langmuir adsorption capacity parameter $\left(\mathrm{L} \mathrm{mg}^{-1}\right), b$ is the Langmuir constant related to adsorption energy $\left(\mathrm{L} \mathrm{mg}^{-1}\right), C_{f}$ is the concentration of the substance in the solution when in equilibrium $\left(\mathrm{mg} \mathrm{L}^{-1}\right), n$ is the adsorption efficiency (absorption intensity) ( $\left.\mathrm{mg} \mathrm{g}^{-1}\right), K_{f}$ is an indicator of adsorption capacity of the material $\left(\mathrm{L} \mathrm{mg}^{-1}\right)$, qe is the concentration of the adsorbate present in the adsorbent when in equilibrium $\left(\mathrm{mmol} \mathrm{g}^{-1}\right), \mathrm{X}_{\mathrm{m}}$ is the adsorption capacity $\left(\mathrm{mmol} \mathrm{g}{ }^{-1}\right), \mathrm{k}$ is the constant bonded to the energy free of sorption $(E)\left(\mathrm{mol}^{2} \mathrm{~kJ}^{-2}\right)$, and $E$ is the Potential of Polanyi $\left(\mathrm{kJ} \mathrm{mol}^{-1}\right)$.

The Langmuir model indicates adsorption per monolayer on the adsorbent surface due to the presence of homogeneous sites of the same energy. The Freundlich isotherm admits a multilayer adsorption process and predicts the heterogeneity of the adsorption sites on the adsorbent surface. The Dubinin-Radushkevich (D-R) isotherm was developed to overcome the limitation of the Langmuir and Freundlich models. The D-R model does not consider the homogeneity of the process and admits that the adsorption potential is constant.

Table II shows the parameters obtained when applying the data obtained with the Langmuir and Freudlich models. Note that the results for the adsorption of E1, EE2, and SMX by the banana peel were not adequately described by the Langmuir model $(E 1=0.861$, EE2 $=0.548, \mathrm{SMX}=0.676)$, but by the Freudlich model, indicating that the adsorption is not limited to a monolayer; saturation occurs, forming other layers (multilayer).

The values of $n$ for compounds E1, EE2, and SMX were 1.138, 1.364, and 1.246, respectively. If $n$ is greater than 1 , this indicates that the high energy sites are occupied by others of lower energy and intensity and the adsorption of the three compounds is favourable. The $\mathrm{K}_{\mathrm{f}}$ values indicate low adsorption of the compounds, as well as a good linearity, indicating that adsorbent-adsorbate interactions occur [40].

The value of the division $1 / \mathrm{n}$ was less than 1 , indicating low heterogeneity of the surface sites and stronger interaction between the adsorbent and the adsorbate. The $\mathrm{K}_{f}$ values indicate low adsorption of the compounds, as well good linearity, indicating that the adsorbent-adsorbate interactions may be of a physical nature [40]. Analysing the two factors ( $\mathrm{n}$ and $\mathrm{K}_{\mathrm{f}}$ ), it was observed that the adsorption process occurs in multiple layers, which is more appropriate for the Freudlich model. 
Table II. Adsorption parameters, E1 (estrone), EE2 (ethinylestradiol) and SMX (sulfamethoxazole) using banana peel as adsorbent $(n=3)$.

\begin{tabular}{|c|c|c|c|c|c|c|c|c|}
\hline & \multicolumn{4}{|c|}{ LANGMUIR } & \multicolumn{4}{|c|}{ FREUNDLICH } \\
\hline & $\mathbf{Q}_{\text {Max }}$ & B & $\mathbf{R}_{\mathrm{L}}$ & $\mathbf{R}$ & n & $1 / n$ & $K_{f}$ & $\mathbf{R}$ \\
\hline E1 & -2.4929 & -0.2525 & 0.8608 & 0.5820 & 1.1378 & 0.8789 & 0.6007 & 0.9868 \\
\hline EE2 & 1.1783 & -1.9186 & 0.5479 & 0.9307 & 1.3639 & 0.7331 & 0.3089 & 0.9948 \\
\hline \multirow[t]{3}{*}{ SMX } & 0.9219 & 0.1323 & 0.6756 & 0.6403 & 1.2458 & 0.8027 & 0.1073 & 0.9889 \\
\hline & \multicolumn{8}{|c|}{ DUBININ-RADUSHKEVICH } \\
\hline & \multicolumn{2}{|c|}{$x_{m}$} & \multicolumn{2}{|c|}{ k } & \multicolumn{2}{|c|}{$E$} & \multicolumn{2}{|c|}{$\mathbf{R}$} \\
\hline E1 & \multicolumn{2}{|c|}{2.0793} & \multicolumn{2}{|c|}{$3.10^{-8}$} & \multicolumn{2}{|c|}{4.083} & \multicolumn{2}{|c|}{0.9926} \\
\hline EE2 & \multicolumn{2}{|c|}{-0.2037} & \multicolumn{2}{|c|}{ 7. $10^{-9}$} & \multicolumn{2}{|c|}{7.453} & \multicolumn{2}{|c|}{0.9899} \\
\hline SMX & \multicolumn{2}{|c|}{-0.2427} & \multicolumn{2}{|c|}{$1.10^{-8}$} & \multicolumn{2}{|c|}{7.071} & \multicolumn{2}{|c|}{0.9960} \\
\hline
\end{tabular}

By analysing the parameters obtained with the Dubinin-Radushkevich isotherm (Table II), physical adsorption is observed since physical adsorption occurs when an E value of less than $8 \mathrm{~kJ} \mathrm{~mol}^{-1}$ is obtained. The chemical adsorption presents values for $E$ between 8 and $16 \mathrm{~kJ} \mathrm{~mol}^{-1}$ [41].

The best fit $(R)$ by the Freundlich and $D-R$ models for the compounds under analysis are expected due to the heterogeneous surface of the adsorbent material resulting from the distribution of the active sites after the adsorption of E1, EE2, and SMX [42].

\section{Adsorption kinetics}

The adsorption kinetics represent the amount of each free compound that is adsorbed in the banana peel, considering the time. The kinetic study of the adsorption of E1, EE2, and SMX with banana peel shows that the removal of the compounds in solution increased with the in contact time, reaching a time of equilibrium of 90 min and a maximum removal of $0.387 \mathrm{mg} \mathrm{g}^{-1}$ for $E 1,0.420 \mathrm{mg} \mathrm{g}^{-1}$ for EE2, and $0.141 \mathrm{mg} \mathrm{g}^{-1}$ for SMX.

The models used to describe adsorption kinetics were: pseudofirst order models (5), pseudosecond order (6) and intraparticle diffusion (7) analysis which describe the adsorption mechanism of the adsorbent-adsorbate systems. The kinetic parameters (Table III) for adsorption were obtained by linear regression using the equations:

$$
\begin{gathered}
\log (q e-q t)=\log (q e)-k_{1} t / 2.303 \\
t / q t=1 /\left(k_{2} q e^{2}\right)+t / q e \\
q t=k_{\text {dif }}{ }^{1 / 2}+C
\end{gathered}
$$

where qe $\left(\mathrm{mg} \mathrm{g}^{-1}\right)$ and qt $\left(\mathrm{mg} \mathrm{g}^{-1}\right)$ are the amounts of E1, EE2 e SMX adsorbed per unit mass of adsorbent at equilibrium and at any time $\mathrm{t}$, respectively, $\mathrm{k}_{1}\left(\mathrm{~min}^{-1}\right)$ is the constant of the pseudofirst order adsorption rate, $\mathrm{k}_{2}\left(\mathrm{~g} \mathrm{mg}^{-1} \mathrm{~min}^{-1}\right)$ is the constant of the pseudosecond order adsorption rate, which is obtained by the angular coefficient of the curve, $\mathrm{K}_{\text {dif }}\left(\mathrm{mg} \mathrm{g}^{-1} \mathrm{~min}^{-1 / 2}\right)$ is the constant of the intraparticle diffusion rate, and $\mathrm{C}$ is the coefficient of linear regression. 
Table III. Kinetic parameters of adsorption of compounds E1 (estrone), EE2 (ethinylestradiol) and SMX (sulfamethoxazole) models by pseudofirst order, pseudosecond order and intraparticle diffusion $(n=3)$

\begin{tabular}{lcccc}
\hline \multicolumn{5}{c}{ Pseudofirst Order Parameters } \\
\hline Compound & $\mathbf{k}_{\mathbf{1}}\left(\mathbf{m i n}^{-1}\right)$ & $\begin{array}{c}\text { qe }(\mathbf{e x p}) \\
\left(\mathbf{m g ~ g}^{-1}\right)\end{array}$ & $\begin{array}{c}\text { qe (calc) } \\
\left(\mathbf{m g ~ ~ ^ { - 1 } )}\right.\end{array}$ & $\mathbf{R}$ \\
\hline E1 & 0.0292 & 0.0387 & 0.00275 & 0.6875 \\
EE2 & 0.0108 & 0.0420 & 0.00150 & 0.6314 \\
SMX & 0.0972 & 0.0413 & 0.02840 & 0.9542 \\
\hline
\end{tabular}

\begin{tabular}{lcccccccc}
\hline & \multicolumn{3}{c}{ Pseudosecond Order Parameters } & & \multicolumn{2}{c}{ Parameters Intraparticle } \\
Diffusion
\end{tabular}

Table III shows that the most suitable model for kinetic adsorption studies is the pseudosecond order model $(\mathrm{E} 1=0.9999$, $\mathrm{EE} 2=0.9999, \mathrm{SMX}=0.9999)$. One factor that corroborates this situation is the proximity between the values of the calculated $q$ and the experimental $q$ of each compound. The constant of adsorption $\left(k_{2}\right)$ of each compound $(E 1=16.371, E E 2=38.359, S M X=8.914)$ indicates a fast adsorption rate in banana peel.

The suitability of the pseudosecond order model indicates that adsorption depends on the amount of the compound and the active sites present in the adsorbent material. Chemisorption can be explained by an ion exchange process between the compounds and the deprotonated hydroxyl groups of the adsorbent material.

Intraparticle diffusion values in Table III show that the Qt versus $t^{0.5}$ graphs did not pass through the origin ( $\mathrm{C}$ value other than zero), indicating that this mechanism is not determinant in the adsorption process. Other mechanisms, such as intermolecular interactions, must act in the adsorption and mass transfer process [43].

\section{Thermodynamic parameters}

The values of the thermodynamic parameters were calculated according to the following equations:

$$
\begin{aligned}
& K_{d}=C_{\text {equlibrium }} / C_{f} \\
& \Delta G=-R T \ln K_{d} \\
& \Delta G^{\circ}{ }_{\text {ads }} / T=\Delta S^{\circ}{ }_{\text {ads }}
\end{aligned}
$$

where $\mathrm{C}_{\text {equilibrium }}$ is the concentration of organic banana peel compounds at equilibrium (mg L-1), $\mathrm{K}_{\mathrm{d}}$ is the apparent equilibrium constant, $\Delta G$ is the Gibbs free energy $\left(\mathrm{J} \mathrm{mol}^{-1}\right), \mathrm{R}$ is the universal gas constant $\left(\mathrm{JK}^{-1} \mathrm{~mol}^{-1}\right), \mathrm{T}$ is the system absolute temperature $(\mathrm{K})$, and $\Delta \mathrm{S}^{\circ}{ }_{\text {ads }}$ is the entropy involved in the adsorption system $\left(\mathrm{J} \mathrm{mol}^{-1} \mathrm{~K}^{-1}\right)$.

The results obtained indicate that the adsorption process is a spontaneous process [negative $\Delta \mathrm{G}$ values for estrone (-6.992), ethinylestradiol (-4.528), and sulfamethoxazole (-1.403)]. The positive 
entropy values $(E 1=23.310, E E 2=15.092, S M X=4.676)$ indicated that the adsorbent material has a substantial number of active sites, that is, adsorption occurs not only on the surface of the adsorbent material, but also in other internal regions [44].

\section{Validation of some analytical method parameters}

Some validation parameters of the analytical method were determined from analyses carried out under the optimized HPLC conditions previously presented in this paper. The limit of detection (LOD) was considered as the lowest concentration of E1 (0.03 mg L-1), EE2 $\left(0.03 \mathrm{mg} \mathrm{L}^{-1}\right)$, and SMX (0.02 mg $\left.\mathrm{L}^{-1}\right)$ that could be detected considering 3 times the signal-to-noise ratio, and the limit of quantification (LOQ) as 5 times the signal noise $\left(\mathrm{E} 1=0.06 \mathrm{mg} \mathrm{L}^{-1}\right.$, EE2 $=0.07 \mathrm{mg} \mathrm{L}^{-1}$, SMX $\left.=0.06 \mathrm{mg} \mathrm{L}^{-1}\right) . A$ satisfactory correlation coefficient was obtained for the analytical signal up to the concentration of 4.0 $\mathrm{mg} \mathrm{L}^{-1}(\mathrm{E} 1=0.9978$, EE2 $=0.9947$, and SMX = 0.9987).

The repeatability of the proposed method was assessed by performing ten consecutive adsorption steps at a concentration level of $500 \mathrm{\mu g} \mathrm{L}^{-1}$ of the compound mixture, and the result was expressed in terms of the relative standard deviation (that value was equal to $2.42 \%$ ). The specificity was investigated to verify the existence of interfering agents in the matrix analyzed.

Due to the absence of a certified material for determination of accuracy, recovery tests were performed using water samples from the public supply system. The samples were fortified by adding $5.0 \mathrm{~mL}$ of an analytical standard of each compound in $20.0 \mathrm{~mL}$ of matrix, corresponding to three levels of the standard curve. As can be seen in Table IV, recovery rates of 70-96\% were achieved.

Table IV. Relative recovery rates of estrone (E1), ethinylestradiol (EE2) and sulfamethoxazole (SMX) in the samples subjected to the proposed extraction method $(n=3)$.

\begin{tabular}{ccccccccccccc}
\hline \multirow{2}{*}{ Sample } & \multicolumn{3}{c}{ Added $\left(\mathrm{mg} \mathrm{L}^{-1}\right)$} & \multicolumn{3}{c}{ Removed $\left(\mathrm{mg} \mathrm{L}^{-1}\right)$} & \multicolumn{3}{c}{ Recovery (\%) } & \multicolumn{3}{c}{ R. S. D. (\%) } \\
\cline { 2 - 13 } & E1 & EE2 & SMX & E1 & EE2 & SMX & E1 & EE2 & SMX & E1 & EE2 & SMX \\
\hline \multirow{3}{*}{1} & 0.5 & 0.5 & 0.5 & 0.36 & 0.38 & 0.35 & 72 & 76 & 70 & 0.89 & 0.77 & 0.46 \\
& 1.0 & 1.0 & 1.0 & 0.84 & 0.92 & 0.8 & 84 & 92 & 80 & 0.22 & 0.42 & 0.84 \\
& 2.0 & 2.0 & 2.0 & 1.44 & 1.88 & 1.67 & 72 & 94 & 83.5 & 0.24 & 0.29 & 0.33 \\
\hline \multirow{3}{*}{2} & 0.5 & 0.5 & 0.5 & 0.4 & 0.44 & 0.36 & 80 & 88 & 72 & 0.26 & 0.19 & 0.47 \\
& 1.0 & 1.0 & 1.0 & 0.86 & 0.9 & 0.73 & 86 & 90 & 73 & 0.55 & 0.57 & 0.67 \\
& 2.0 & 2.0 & 2.0 & 1.78 & 1.92 & 1.47 & 89 & 96 & 73.5 & 0.75 & 0.76 & 0.66 \\
\hline \multirow{3}{*}{3} & 0.5 & 0.5 & 0.5 & 0.37 & 0.41 & 0.39 & 74 & 82 & 78 & 0.49 & 0.62 & 0.14 \\
& 1.0 & 1.0 & 1.0 & 0.82 & 0.94 & 0.86 & 82 & 94 & 86 & 0.38 & 0.84 & 0.74 \\
& 2.0 & 2.0 & 2.0 & 1.84 & 1.59 & 1.42 & 92 & 79.5 & 71 & 0.73 & 0.76 & 0.67 \\
\hline
\end{tabular}

The literature presents adsorption studies of the same compounds investigated in this work, but with different adsorbents, and percentages of removal very close to the values presented in this work with banana peel. As is the case with the use of active charcoal for estrone with removal between 88.0 and $94.0 \%$ [44], Polyamide 612 with $72.5 \%$ removal of ethinylestradiol [37], and removal of $68.0 \%$ of sulfamethoxazole using activated carbon [45]. The adsorbent under study is advantageous with removal of more than $80 \%$ for $\mathrm{E} 1$ and EE2 and $70 \%$ for SMX in the samples analyzed. Note that the percentages of removal mentioned above are close to the values found in this study with the use of the banana peel, a fact that shows that this natural adsorbent is as effective as the others found in the literature. 


\section{CONCLUSION}

The proposed method was suitable for adsorption and quantification of compounds E1, EE2, and SMX in aqueous solutions. The banana peel sample was efficient in the adsorption process, with removal percentages higher than $70 \%$. The suitability of the Freundlich model showed that adsorption occurs in several layers.

The results concerning kinetic adsorption showed a better fit to the pseudo-second order model. The results of the thermodynamic parameters indicate spontaneous adsorption.

Based on the reported data, it can be inferred that the banana peel proved to be a natural adsorbent suitable to be used efficiently in the removal of E1, EE2, and SMX from aqueous matrices.

Manuscript submitted: Oct. 19, 2018; revised manuscript submitted: Dec. 31, 2018; revised for the $2^{\text {nd }}$ time submitted: March 18, 2019; revised for the $3^{\text {rd }}$ time submitted: May 5, 2019; accepted: June 10, 2019; published online: July 04, 2019.

\section{REFERENCES}

1. Lei, M.; Zhang, L.; Lei, J.; Zong, L.; Li, J.; Wu, Z.; Wang, Z. Biomed. Res. Int. 2015, 1, pp 1-12 (DOI: http://dx.doi.org/10.1155/2015/404796).

2. Geissen, V.; Mol, G.; Klumpp, E.; Umlauf, G.; Nadal, M.; Van der Ploeg, M.; Van de Zee, S. E. A. T. M.; Ritsema, C. J. International Soil and Water Conservation Research. 2015, 3 (1), pp 57-65 (DOI: http://dx.doi.org/10.1016/j.iswcr.2015.03.002).

3. Bennasroune, A.; Rojas, L.; Foucaud, L.; Goulaouic, S.; Laval-Gilly, P.; Fickova, M.; Couleau, N.; Durandet, C.; Henry, S.; Falla, J. Int. J. Immunopathol. Pharmacol. 2012, 25 (2), pp 1-12 (DOI: http://dx.doi.org/10.1177/039463201202500206).

4. Vihma, V.; Wanga, F.; Savolainen-Peltonena, H.; Turpeinend, U.; Hämäläinend, E.; Leideniuse, M.; Mikkolaa, T. S.; Tikkanena, M. J. J. Steroid. Biochem. Mol. Biol. 2016, 155, pp 120-125 (DOI: http://dx.doi.org/10.1016/j.jsbmb.2015.10.004).

5. Lark, S. M. The estrogen decision self help book. Celestial Arts: New York. 320, 1999.

6. Johnson, A. C.; Belfroid, A.; Di Corcia, A. Sci. Tot. Environ. 2000, 256, pp 163-173 (DOI: http:// dx.doi.org/10.1016/S0048-9697(00)00481-2).

7. Brunton, L. L.; Lazo, J. S.; Parker, K. L. Goodman \& Gilman as bases farmacológicas da terapêutica. Rio de Janeiro: McGraw-Hill, 2007, p 1821.

8. Ariese, F.; Wilfried, H. O. E.; Dick, T. H. M.; Sijm, C. Environ. Toxicol. and Pharmacol. 2001, 10, pp 65-80 (DOI: http://dx.doi.org/10.1016/S1382-6689(01)00090-4).

9. Errayess S. A.; Lahcen A. A.; Idrissi L.; Marcoaldi C.; Chiavarini S.; Amine A. Spectrochim. Acta, Part A, 2017, 181 (15), pp 276-285 (DOI: http://dx.doi.org/10.1016/j.saa.2017.03.061).

10. Fent, K.; Weston, A. A.; Caminada, D. Aquatic. Toxicol. 2006, 76, pp 122-159 (DOI: http://dx.doi. org/10.1016/j.aquatox.2005.09.009).

11. Khalaf, H. S.; Dikran, S. B.; Mohammed, A. K. Jour. for Pure \& Appl. Sci. 2014, 27 (3), pp 365379 (DOI: http://dx.doi.org/10.13140/RG.2.1.2209.4488).

12. Iquego: sulfametoxazol+trimetoprima. Dra. Maria Aparecida Rodrigues. Goiás. Bula de remédio. Indústria Química do Estado de Goiás S. A.

13. Reis Filho, R. W.; Araújo, J. C.; Vieira, E. M. Quím. Nova. 2006, 29 (4), pp. 817-822 (DOI: http:// dx.doi.org/10.1590/S0100-40422006000400032).

14. Rovani, S.; Censi, M. T.; Pedrotti, S. L.; Lima, E. C.; Cataluna, R.; Fernandes, A. N. J. Hazard. Mater. 2014, 271, pp. 311- 320 (DOI: http://dx.doi.org/10.1016/j.jhazmat.2014.02.004).

15. Cordeiro, G. A.; Zamora, P. P.; Nagata, N.; Pontarollo, R. Quim. Nova. 2008, 31 (2), pp. 254-260 (DOI: http://dx.doi.org/10.1590/S0100-40422008000200012). 
16. Melo, S. A. S.; Trovó, A. G.; Bautitz, I. R.; Nogueira, R. F. P. Quím. Nova. 2009, 32, pp 188-197 (DOI: http://dx.doi.org/10.1590/S0100-40422009000100034).

17. Bila, D. M.; Dezotti, M. Quím. Nova. 2003, 26, pp 523-530 (DOI: http://dx.doi.org/10.1590/ S0100-40422003000400015).

18. Bhatnagar, A.; Sillanpääb, M. Chem. Eng. J. 2010, 157, pp 277-296 (DOI: http://dx.doi.org/10.1016/j.cej.2010.01.007).

19. Zhang, Y.; Zheng, R.; Zhao, J.; Ma, F.; Zhang, Y.; Meng, Q. Biomed. Res. Int. 2014, 12 (2) (DOI: http://dx.doi.org/10.1155/2014/496878).

20. Gil, A.; Taoufik, N.; García, A. M.; Korili, A. S. Environ. Technol. 2018, 19, pp 1-14. (DOI: http:// dx.doi.org/10.1080/09593330.2018.1464066).

21. Sousa, F. W.; Oliveira, A. G.; Ribeiro, J. P.; Rosa, M. F.; Keukeleire, D.; Nascimento, R. F. J Environ Manage. 2010, 91 (8), pp 1634 - 1640 (DOI: http://dx.doi.org/10.1016/j.jenvman.2010.02.011).

22. Abdelwahab, O.; Nasr, S. M.; Thabet, W. M. Alexandria Eng. J. 2017, 56 (4), pp 749-755 (DOI: http://dx.doi.org/10.1016/j.aej.2016.11.020).

23. Wang, F. Y.; Wang, H.; Ma, J. W. J Hazard Mater. 2010, 177, pp 300-306 (DOI: http://dx.doi.org/10.1016/j.jhazmat.2009.12.032).

24. Mafra, M. R.; Mafra, L. I.; Zuim, D. R.; Vasques, É. C.; Ferreira, M. A. Braz. J. Chem. Eng. 2013, 30 (3), pp 657 - 665 (DOI: http://dx.doi.org/10.1590/S0104-66322013000300022).

25. Hussein, H. S.; Shaarawy, H. H.; Hussien, N. H.; Hawash, S. I. Bulletin of the National Research Centre. 2019, 43 (26), pp 1-9 (DOI: http://dx.doi.org/10.1186/s42269-019-0058-1).

26. Gupta, H.; Gupta, B. Desalin. Water Treat. 2015, 57 (20), pp 1-12 (DOI: http://dx.doi.org/10.1080/19443994.2015.1029007).

27. Silva, C. R.; Gomes, T. F.; Andrade, G. C. R. M.; Monteiro, S. H.; Dias, A. C. R.; Zagatto, E, A. G.; Tornisielo, V. L. J. Agric. Food Chem., 2013, 61 (10), pp 2358-2363 (DOI: http://dx.doi.org/10.1021/jf304742h).

28. Mondal, N. K.; Kar, S. Appl. Water Sci. 2018, 8 (6), pp 1-12. (DOI: http://dx.doi.org/10.1007/s13201-018-0811-x).

29. Memon, J. R.; Memon, S. Q.; Bhanger, M. I.; Memon, Z.; Turki, A. El.; Allen, G. C. Colloids Surf B Biointerfaces. 2008, 66, pp. 260-265

(DOI: http://dx.doi.org/10.1016/j.colsurfb.2008.07.001)

30. Corti, G. S.; Botaro, V. R.; Gil, L. F.; Gil, R. P. F. Polímeros: Ciência e Tecnologia. 2004, 14 (5), pp 313-317 (DOI: http://dx.doi.org/10.1590/S0104-14282004000500007).

31. Akhter, M. S.; Chughtai, A. R.; Smith, D. M. J. Phys. Chem.1984, 88, pp. 5334 - 5342 (DOI: http://dx.doi.org/10.1021/j150666a046).

32. Fanning, P. E.; Vannice, M. A. A. Carbon. 1993, 31, pp.721-730 (DOI: http://dx.doi.org/10.1016/0008-6223(93)90009-Y).

33. Gomez-Serrano, V.; Pastor-Villegas, J.; Perez-Florindo, A.; Duran-Valle, C.; Valen-Calahorro, C. J. Anl. Appl. Pyrol. 1996, 36, pp 71-80 (DOI: http://dx.doi.org/10.1016/0165-2370(95)00921-3).

34. Ribeiro, A. V. F. N.; Belisário, M.; Galazzi, R. M.; Balthazar, D. C.; Pereira, M. G.; Ribeiro, J. N. Electron. J. Biotechn. 2011, 114, pp 1-10 (DOI: http://dx.doi.org/10.2225/vol14-issue6-fulltext-8).

35. Ribeiro, A. V. F. N.; Silva, A, R.; Cunha, T. P.; Santos, R. T. L.; Oliveira, J. P.; Pereira, E. V.; Licinio, M. V. V. J.; Pereira, M. G.; Santos, A. V.; Ribeiro, J. N. J. Environ. Prot. 2016, 7, pp 1850-1859 (DOI: http://dx.doi.org/10.4236/jep.2016.712147 ).

36. Bajpai, A. K.; Rajpoot, M. Adsorption Behavior of Sulfamethoxazole Onto na Alumina- Solution Interface. Bull. Chem. Soc. Jpn. 1996, 69 (3), pp 521-527

(DOI: http://dx.doi.org/10.1246/bcsj.69.521).

37. Han, J.; Qui, W.; Cao, Z.; Hu, J.; Gao, W. Water Res. 2013, 47, pp 2273- 2284 (DOI: http:// dx.doi.org/10.1016/j.watres.2013.01.046). 
38. Marques, N. J. O.; Bellato, C. R.; Milagres, J. L.; Kenia, D. P.; Alvarenga, E. S. J. of the Brazil. Chem. Society. 2013, 24, pp 121-132

(DOI: http://dx.doi.org/10.1590/S0103-50532013000100017).

39. Dash, M.; Chiellini, F.; Ottenbrite, R. M.; Chielline, E. Progr. in Polym. Sci. 2011, 36, pp 9811014 (DOI: http://dx.doi.org/10.1016/j.progpolymsci.2011.02.001).

40. Martínez, J. I.; Calle-Vallejo, F.; García-Lastra, J. M.; Rossmeisl, J.; Koper, M. T. M. Phys. Rev. Lett. 2012, 108, pp 103-116 (DOI: http://dx.doi.org/10.1103/PhysRevLett.108.116103).

41. Sljivić, M.; Smičiklas, I.; Pejanović, S.; Plećaš, I. Comparative study of $\mathrm{Cu}^{2+}$ adsorption on a zeolite, a clay and a diatomite from Serbia. Applied Clay Science. 2009, 43, pp 33-40 (DOI: https://doi.org/10.1016/j.clay.2008.07.009).

42. Oliveira, T.; Guégan, R.; Thiebault, T.; Milbeau, C.; Muller, F.; Teixeira, V.; Giovanela, M.; Boussafir, M. J Hazard Mater. 2017, 323, pp 558-566 (DOI: http://dx.doi.org/10.1016/j.jhazmat.2016.05.001).

43. Febrianto, J.; Kosasih, A. N.; Sunarso, J.; Ju, Y. H.; Indraswati, N.; Ismadji, S. J. Hazard. Mater. 2009, 162, pp 616-645 (DOI: http://dx.doi.org/10.1016/j.jhazmat.2008.06.042).

44. Gökçe, C. E.; Arayici, S. Desalin. Water Treat., 2015, 57 (6), pp. 2503-2514 (DOI: http://dx.doi.org/10.1080/19443994.2015.1034183).

45. Lember, E.; Pachel, K.; Loigu, E. "Environmental Engineering" $10^{\text {th }}$ International Conference, 2017 (DOI: http://dx.doi.org/10.3846/enviro.2017.082). 